\title{
Juan Parra del Riego $\left(^{*}\right)$
}

\author{
Por Manuel Beltroy
}

Ha querido la Comuna de Barranco, haciendo honor a los fueros de su Ciudad, a la tradición artística de la Gran Lima y a los blasones culturales de nuestra Patria, honrar la memoria del que fuera su cantor: Juan Parra del Riego, dando su nombre a esta Plazoleta, que habrá de perennizarla en el recuerdo de las generactones venideras barranquinas y peruanas.

En este hermoso rincón barranquino -uno de los más sugerentes y saudosos de esta Villa floral y marina-; en tan bello recodo del Balneario, en el cual se refugia y guarecen contra el implacable avance ldel urbanismo capitalino y metropolitano, la gracia agreste y reb encanto rural, que aún, conservan las urbes provincianas de nuestras viejas poblaciones de vacación $Y$ veraneo; en este seguro de quietud y añoranza, resurgirá de la doble lejomía del thempo y del espacio y se alzará aquí para siempre la figura del Poeta ausente, como numen tutelar de su Pue blo, en el augusto y evocativo marco que le prestarán el barranco paterno, los árboles custodios, el Puente del amor, el mar dormido entre las frondas y el terso palio azul del cielo.

Lindo paraje para hospedar definitivamente al Poeta siquiera sea en efigie, de vuelta, al cabo de largo peregrinaje, de sus andanzas de lírico vagabundo; para reintegrar al hijo pródigo al seno de su hogar, a fin de que la enriquezca con el tesoro poético allegado en su agitada romería a irueque del dispendioso derro-

(*) Discurso pronunciado por el Doctor Manuel Beltroy en Barranco, con ocasión de la ceremonia de inauguración en Barranco de la Plazoleta que lleva el nombre del Poeta. 
che de su sangre y su alma; para inscribir en su lápida, como en la de Abelardo el amargo epítafio: "Requiescat de labore doloroso et amore", "descansa de una labor y un amor dolorosos".

$Y$ hermoso ejemplo el que nos da el Ayuntamiento de Barranco al hacer justicia a uno de sus ciudadanos preclaros, restaurando con ello sus valores ancestrales, reviviendo sus costum. bres artísticas, renovando su antiguo culto al Espíritu y al Arte. Con esta ceremonia y con la romería cívica que la seguirá, la ciudad de los Poetas, Barranco la romóntica, nuestra Bienamada, que no se cansa de soñor en su antepecho enguimaldado, frente al maravilloso panorama marítimo y celeste, recobra su prestancia y gentileza estética y espiritual, reanuda su prosapia helénica y su educación latina, reafirma su tradición hispánica y acrisola el purísimo oro de su herencia peruana.

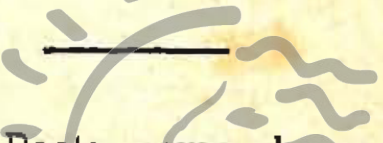

Quien frecuentó al Poeta, como el que habla; quien gozó el privilegio de su amistad, puede afirmar, como testigo de excepción que, él vivió su vida en poesía; que hizo de la poesía su vida: que fué Poeta "total", si se permite la palabra; que en su persona y en su obra se dió y realizó la ecuación perfecta de vida y poesía, hasta tal punto que si quisierg deftnírsele se le podría aplicar modificada, Ia inscripción tumbal del Petrarca: "su oficio fué la Santa Poesía".

La ley de este poeta de nuestra estirpe, perteneciente por el espíritu a la familia excelsa de "los que en arte viven y mueren en belleza", fué, sin metáfora, efectivamente, vivir en arte $\mathrm{y}$ morir en belleza, a fin de que en su tierra natal y en su solar latinoamericano - la Patria grande, a medida de su alma- el ATte viva cada vez más y la Belleza no muera nunca. Su ley fué la ley suprema de nuestra Raza; la que hace de lo Bello el hilo de Ariadna en el laberinto del Cosmos, la que alza una ínsula de permanencia, de realidad $y$ de reposo en el mar sin orillas del ser, la que forja un ligamen fundamental entre los hombres en la vo. rágine del devenir.

A esta ley obedeció su personalidad como la aguja de marear señala al norte, automática, eléctrica, írresistiblemente. Su vida entera fué una carrera vertiginosa en pos de la Belleza, una travesía febril hacia esta mágica Montaña de Imán, en cuyos flancos, "donde todos se han lacerado sucesivamente", iría él, por úl- 
timo, a estrellarse $\mathrm{y}$ fundirse, como la nave del príncipe oriental en el monte magnético;

Poetas hay en quienes la poesía es serenidad lacusire de ocaso, como en Lamartine; es en otros beatitud mirífica, así en Rosetti; en algunos, exaltación mística o ensoñación alucinada, tal en Baudelaire, en Blake o Poe; en nuestro poeta fué fjebre de vida $\mathrm{y}$ afirmación de vida; sentimiento $\mathrm{y}$ expresión desaforados de vitalidad creadora, de alegría vital, de pathos vivífico.

Jamás en América, en toda la vastedad del Nuevo Mundo. desde los días del panida Whilman, sonó una voz, cantando en nuevos ritmos vivificantes una canción tan enamorada del Vivir y de la Actividad, de la Fuerza creadora; tan embriagada de acción, de ímpetu generador; pero nunca tampoco en nuestro Continente surtidor semejante de Amor y de Entusiasmo brotó de corazón tan atormentado por el dolor y tan desolado por la angustia. En esta contradicción entre el delirio vitalista de su canto y la hondura mortal de donde mana, radica, a mi juicio, el patetismo de su poesía y su alta calidad estética, Cuanto más sufre el Poeta, cuanto más lo atenaza la angustia, tanto más pura $y$ luminosa se alza la columna de fuego de sus himnos, como esos rútilos geysers que suben a la superficle del océano de los volcanes submarinos. Y, con clara conciencia de la inanidad del mundo, del mal de la vida, dejla pérversidad del género humano, empujado por una tremenda e irreprimible eneráía cósmica, obedeciendo al imperativo inflexible del Ser, da rienda suelfa" a la onda lírica de sus cantos, que celebran el innumerable triunfo del Amor y de la Vida. Así, canta :

Yo amo el sol. Amo la vida. Creo. Camino. Sueño. iTodo el licor salvaje de la acción y el ensueño! ¡Mujeres, nủbes, árboles, aeroplanos, banderas! ¡Yo fuí por el mundo

con los colorados zapatos calientes de mi corazónl Y vi el odio. Vi el mal. Vi la envidia y la muerte. Pero vi que el sol era siempre en todo más fuerte. $\mathrm{y}$.en un alcohol celeste me herví mós la emoción; y me dije en lo íntimo del pecho dolorido:

hoy que ser como el mar:

Recogerse en la noche, violento, oscurecido, $\mathrm{y}$ amanecer azul $\mathrm{y}$ atacar . . . atacar. 
"Por el Dolor a la Alegría", el lema beethoviono, máxima norma de los grandes artistas, es el canon de su inspiración. Y, sobre el cráter flamígero de su traggedia y su desgarramiento, surgen, vapores de oro en cielos de cobalto, sus más jovioles y armoniosos poemas:

Yo me dije, haciendo sangre mi contemplación sutil, sólo casta, alegre, pura, compasiva, alta y viril, yo te llevaré, alma mía, por toda la tierra hostil.

(Palomas)

El heroismo magno de creer por creer, de engendrar, "a pesar de la Muerte y del sepulturero", como decía Mistral, de afirmar ante la mutabilidad de la Naturaleza y la fatalidad del aniquilamiento individual, la eternidad del Todo, la inmortalidad de la Vida, es el alma misma de su espléndido y ardiente lirismo, que le presta la virlud de su Salterio y de un Himnario, en que la $\mathrm{Hu}-$ manidad se enciende y fraterniza como en el Allegro de la Sinfonía Coral :

Oh, Capitán, mi capitán, imi Capitánl

Tú dices: todo vuelve.

Pero yo contra tu pecho grito: [nada vuelyel

iLa fuerza es iv locos ae confianza hastal tin! con nuestroş corazones sonoros como truenos marchando hacia adelante sin cesar.

(Wolt Whitman)

Hoy sólo hay el alma que quiere subir. la fe vencedora;

allá está la estrella caliente y sonora y hacia ella hay que ir.

¡Hacia ella nos vamos, locos de confianzal ¡Fuego, amor, azote!

Como fue Unamuno, peleando en la luz, y nuestro querido señor Don Quijote y nuestro fantástico padre Jesús.

(Marcho Unamuno)

Fe maravillosa, fe sublime, finalidad sin fin, virtud propia del Arte, verdadera quintaesencia de poesía, que, creando yn mag- 
nífico mundo de Belleza y de Amor sobre el abismo del Infinito, abraza en sus cálidas ondas a todo el Orbe, como en el evangelio nistzscheano o whitmaniano:

Yo soy el que ha corrido, con un corazón loco de contianza, a fraternizar por todos los caminos con los hombres. Yo soy amigo de acróbatas, de tipógrafos, de enfermos, de campesinos y de boxeado

|Arriba las almas!

cres...

iLa caballería, la música,

los jardines, los flores, el mar y las mujeres!

Lo que hay arriba de la Cruz del Sur

y lo que hay debajo de los párpados fantásticos de los lo-

ILa tolal sinfonía de la tierra y de la vidal

(cos.

¡El hijo de Dios que vino con sus cantos de fuerza y ez-

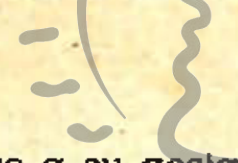

(peranza!

El poeta nace a su gesta trashumante en el paraje peruano más salutífero y opimo, en la ciudad de Huancayo, cabeza vivaz de un Departamento doblemente central en el Perú; por su ubicación geográficáay por sucimportancíanen lafeconomía y en la cultura peruana. En su valle ubérrimo y arcádico, Mesopotamia nuestra, al amor de un sol clemente y de una tierra maternal, bajo un cielo de diafanidad $y$ tersura cristalinas $y$ entre fragantes cortinados de bosques, crece y se multiplica una raza fuerte, pacífica e inteligente, apta para todas las labores, diestra en tadas las artes. En esia atmósfera saludable y fertilísima se nutrió su primera infancia, $y$ en sus divinas calmas y sus bravas tormentas encendieron con fuego vital su estro naciente. Por eso, cantaría, desde Montevideo, con la nostalgia del terruño:

INo hay nada en el mundo, nt el sol ni la guerra como las salvajes vientos de esta tierral Yo aprendí en vosotros mis rudas tonadas $y$ el ir por el mundo como las cascadas: a saltos, impulsos, carreras aladas y no se qué angustia de cumbres sagradas 
que me hace ser todo velas desplegadors para las más hondas rutas ignoradas

Vientos, vientos, vientos de mi tierra, leones que el viento enmelena con sus algodones. vámonos frenéticos por las poblaciones de esta vieja América con sus tradiciones que hacen de las gentes siervos y bufones, y arrollantes, trágicos, rompamos canciones que agiten como émbolos a los corazones. refresquen las almas y alcen las pasiones en las rojas lanzas de otras rebeliones.

\section{(Los Vientos del Perú)}

Otro ambiente, de opuesto clima peruano, laxo y sedante, iba a atemperar en el mozo el hirviente licor serrano bebido por el infante. El balneario limeño de Barranco vería nacer al poeta y lo ungiría. Eran aquellos días barranquinos, doblemente arcádicos, por la mansedumbre pueblerina y por los árcades que a favor de su paz y dulzura poetizaban. Eran los días en que $l_{\alpha}$ antigua Villa de San José de Surco, despertando de su legendaria modorra, en los rústicos ranchos y en torno a la ermita del buen $P \propto-$ dre Abregú, entre la altanera Chorrillos y la recóndita Miraflores, empezaba a hacer píninos de ciudad, remozada y vestida de nuevo por paternal burgomaiestre com las galas de sus flamantes plazas y paseos y su moderno establecimienta balneario. Todavía las huertas antanionas entreabrian sus misteriosas frondosidades a las incursiones de los pilluelos; en esta Bajada de los Baños, umbrosos ficus centenarios cobijaban con sus guedejas patriarcales a las parejas amorosas en las bancas, pues

tienen esa actitud de los abuelos cuando cuentan sus vidas y fracasos, que miran la dulzura de los cielos y abren la patriarcal paz de sus brazos;

(Canto a Barranco)

bajo las lilas de los jacarandás tejíanse romances lugareños y chismes aldeanos, al perezoso ritmo de las retretas provincianas; en semanas de huelga llegaban al romántico andén de la Estación, hirviente de bullicioso y novelero gentío parroquiano, locomotoras sofocadas y chispeantes, como señoras en retardo, remolcando vie- 
jísimos vagones, y desde las torrecillas de San Francisco, a la hora crepuscular, el Angelus vertía piadosamente sobre el poblado la seráfica unción de sus campanas.

Un semanaric fino, Balnearios, fundado y dirigido por ei espiritu selecto y renovador de Alfredo Muñoz, abrió cauce en la ciudad novel a la surgente literaria que en ella afloraba y una pléyade de poetas nuevos afluyó con sus producciones a llenarlo. Casi todos los escritores hoy consagrados hicieron allí sus primeras armas. Juan Parra contaba a la sazón diecinueve años, y en los Juegos Florales organizados por la Municipalidad barranquina, en Noviembre de 1913 ,recibió la Flor Natural como premto a su Canto a Barranco, rosario lírico de catorce sonetos, en que ensartara ingenuamente sus impresiones cándidas de la iglesia parroquíal y del Parque, de la Ermita y del Mor.

Por entonces, aún mozalbete, Parra estaba ya poseído de la inquietud febril y andariega que lo llevara, en su existencia y en su obra, por campos lejamos, aguijado por esa hambre de lo bello y esa sed de la acción, que lo definen. En la palidez de su amplia frente, enmarcada por negros mechones laclos, en la movilidad y hondura de sus ojos inquisitivos, en el rictus de sus labios óvidos, en la vibración metálica de su voz, se revelaba la agonía del demonio interior que lo forturaba.

Mi añoranza amical se complace en evocar aquellas noches tibias de verano en que, mientas por la ventana abierta a la Avenida entraban con las ráqagas marings el aroma de la madreselva y el anís y la fanfarria de las retretas, leímos bajo la lámpara de mi biblioteca de estudiante los poetas franceses de nuestra predilección: la Elegía del bachiller hijo de labriegos que murió mientras aprendía a Virgilio, de James; las estancias melancólicas y aristocráticas de Samain; la balada de la campesina difunta, de Poul Fort; las épicas tiradas versolibristas de Las Ciudades Tentaculares de Verhaeren, y la velada concluía con una paseata lírica por la avenida solitaria, que ya empañaba la neblina nocturna, hasta la cossa del poeta.

Pero la placidez y la monotonía del Balneario, su ambiente burgués y nuevorrico empezaban a hostigar sus nervios. Un buen día, no pudo más, y sacudiendo el sopor lugareño, fuese al Norte, atraído por la fama y las primeras hazañas de La Bohemla de Trujillo. La amistad que entabló con ese vigoroso grupo literanio innovador, accudillado por escritores hoy consagrados, como Vallejo. Garrido y Spelucín, de cuyas ideas y trabajos informó en pintores. 
co ensayo, que se públicó en "Balnearios" con el título mencionado, sobreexitó sus anhelos de liberación y expatriación. La propia ciudad de Lima, a pesar de su ebullición intelectual y artística iniciada por los círculos de Contemporóneos y Colónida y sostenida por las polémicas que éstos suscitaban a los epígonos del Romanticismo supérstite y del modernismo anquilosado, era ya estrecha para su ideal; por donde, poco fué el tiempo que, a su regreso de Trujillo, permaneció entre la Capital, el Balneario y el Puerto, verdaderamente uncido en éste a un insignificante puesto burocrático del cual se desasió otro día, bruscamente, para seguir el rumbo que le señalaba su astro. Entonces entonó, punzado por el dolor de la partida y el odio contra la atmósfera que pugnaba por ahogarlo, así como inflamado por la esperanza de encontrar horizontes proplcios, su primer canto original, mezcla de confesión, de imprecación y de cugurio:

Mañana, con el alba, yo me iré, madre mía, mascando mi secreto de sangre y de ironía.

Solo quiero partir, irme, no importa dónde:

Yo tenía una fuerza

que esta ciudad, astuta, comercial y perversa

la hizo fríg y triste .

Maquinista oacróbata, marinero o ladrón. yo portiré mañana, madre mía. Es pasión.

Es instinto este loco deseo de portir.

Poeta de las máquinas, del sol y de la tierra, yo necesito todos mis nervios con su guerra.

Vivir es ir, pelear, vencer y destrozarse.

Quien lleva más la luz es el que más la esparce.

Mañana ya os veré, cielos altos y plenos, estaciones queridas, noche loca de truenos. ¡Mañana ya os veré mar de los grandes cielos que lavan las heridas de los hombres . . . pañuelos de los adioses finosl jMar donde el corazón hace más pura su alta y solitaria pasiónl [Qué concordancias fuertes de mi ser con las cosas! Mi alma se lanza en todas sus ruedas misteriosas. 1Qué salvajes y frescas serenatas de luna! Mis versos van soñando mi cálida fortuna. 
Embriaguez de espacio libre $\mathrm{y}$ de aventura infinita, voluptuosidad ante la inminencia de ejercer plenamente sus facultades y su alto oficio de cantor, hinchan estos versos de despedida, más también los hace temblar la ternura de la separación.

Y pasaron, en borroso desfile y en teoría polícroma, los puertos del Pacífico austral. hasta que asomó al cabo Valparaíso, con las gemas de su caserio sobre la felpa verde de sus contiles. En Santíago, el abrazo cordial de esa gran maestra de poesía y primera poetisa de maestros que es Gabriela Mistral, le revela a la pars el hondo lirismo de la nueva generación de Chile y el mensaje dramático de su tierra. Allí escuchará el primer aplauso continental a su poesía, $y$, tras breve colaboración en los diarios del Mapocho, tramontará los Andes y se echará a nadar espiritualmente en el mar de la Pampa argentina:

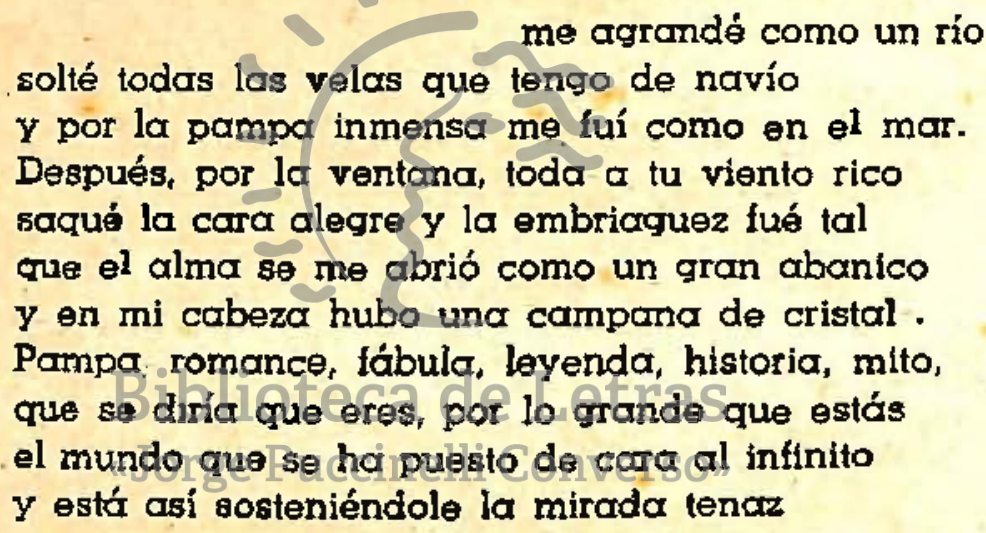

Buenos Aires, la "ciudad tentacular", la Babilonia del sur. reavivó en el estro del poeta la influencia verhaereniana, y con su río y su Pampa y su torbellino humano le inspiró las dimenstones y las músicas de sus polirritmos; pero, al mismo tiempo, la soledad desolada del paisaje pampeano desata la otra vena de su lirismo, la angustia trémula de sus Nocturnos:

Héme aquí en la gran noche de la Pampa, perdido bajo el grandioso y loco órbol estremecido de las estrellas, dándoles a las sombras ml paso con un azul y helado corazón de payaso.

Héme aquí por primera vez frente a mi destino. tamtástico de pena. y horror en el camino. Triste de la alegría y triste del pensamiento. seguro de que todo se acuba a olvido lento. 
A.Jma mía nocturna, alma mía anhelonte, ¡cuánto amor! cuánta muertel jcuántó sed! jeuánto grito! en este enloquecido corazón trashumante lleno de un solitario sufrimiento infínito.

(Nocturno No 5)

Y llega a Montevideo el peregrino lírico, a la ciudad que lo aguardaba، a la ciudad hecha para él, sin que él lo supiera, a la Atenea americana, por la feminidad de su cuerpo y por el temple viril de su alma, hermosa y fuerte como Palas, clásica como la Diosa Doncella, en virtud de la perfecta correspondencia entre su tierra y su mente; a la Ciudad que en la Acrópolis do su Cerro, que avizoró y descubrió el descubridor como un símbolo, ha encendido una lámpara de cultura que es faro de salud para nuestra gente.

Entronizada al borde de las therras platenses, en el grandioso paraje donde el soberbto Plata se une en gigantesco abrazo con el Atlántico, abrazo que los Alislos y el Pampero zarandean desde las afueras del Océano hasta las concavidades del Estuario; reclinada en su blandas colinas. coronada con las frondas de sus plátanos, albeanle de mármoles. cúrea de sol, sonriendo con los ojos zarcos de su cielo a todos los viandantes de la tierra, la Parthenos platina abrílsu templo al bienvenida buscador de belleza.

Eran los días en que la Virgen del Plata, a la diadema de su hermosura física unía la de su plenitud democrática: un régimen liberal socialista, en que la libertad y el orden se hermanaban, abría a los derechos y a las actividades del pueblo uruguayo cauce tan amplio como el del poderoso caudal platense; por él discuIria, mansa y opulenta, la vida ciudadana a fecundar todas las instituciones públicas y a expresarse con frescor primaveral en los campos de la industria, la ciencia y el Arte. La lucha equilibrada de las grandes fuerzas políticas, como el vaivén de las marejadas maritima y fluvial; el sentimiento de la libertad y del imperio del derecho; una política providente en lo interno y cosmopolita en el orden internacional; un pulular y un florecer de aptitudes, de energías, de iniciativas, de cudacias, a favor y a estímulo de este clima social, uniéndose a la dulzura, plenttud y gracia del ambien. te geográfico, daban al Uruguay y a su primera Urbe un encanto vital casi inefable. 
Por las anchas avenidas montevideanas que, como cintas de raso, ciñen la Ciudad desde la cima hasta el mar, ondulando en declive bajo las copas de sus plátanos; por sus pulcras plazas y sus irondosos parques; en los miradores de sus ramblas, asomadas a las ondas, gentil cinturón urbano; desde el rebullicio fabril de la Fortaleza del Cerro y el abigarramiento portuario hasta la elegancia sedante de Malvín; entre los rosedales del Prado, alentaba una atmósfera vernal que escanciaba la alearía de vivir.

He aquí que el poeta errante llega a esta Arcadia y en ella encuentra, en la hospitałidad de su latitud física y cultural, la $a-$ cogida afectuosa del círculo fraternal que anhelaba. Dejémosle hablar:

"Tiro atrás mi corazón y ¿qué mirơ Es el año de 1917, de mi llegada a Montevideo. |Florencio Sánchezl ¡Delmira Agustinil |Rafael Barretl ¡Herrera y Reissigl He aquí lo que iba sonando en $\mathrm{ml}$ corazón mientras hacía mis prlmeras caminatas por una ciudad alegre y ventilado, rodedda de mar por todas partes como un buque, y con no se qué luz, y que intimidad, y qué simpatía que inspiraba tan aplacadores sentimientos de confianza al espíritu".

"Y he aquí que fué la noche. La ciudad sacó todas sus joyas de luz eléctrica y se llenó de una belleza más misteriosa $y$ fina en el ondularmiento rara de sus calles. $Z Y$ los artistas? Como en París y Madrid, en Montevideo habia que ir a buscarlos a un caté. Y fué en un cafe, peronen un café sin èsa cosa estrepitosa, reviela y melancólica de los de París y Madrid, donde conocí a Carlos Sabat Ercasty . . ." Tiro atrás mi corazón, y ¿qué miro? Es una sinfonía de ideas y pasión ${ }_{i}$ su silueta sobre el tiempo".

"Y al puerto nos íbamos en la hora de los hombres azules, de las casetas giratorias de las grúas y las barcas, junto a las dársenas, como grandes manos ahuecadas en el ruego de Europa a América. 'Qué cielo, esos días! Esos cielos de un azul celeste eléctrico y helado que sólo se ven en Montevideo después de los "pamperos" limpiadores, urnas de sensibilidad infinita, de maravillosa poesía, que indican que el mito de la tierra es paz y trabajo, amor y voluntadl ... Y nos haciamos esas caminatas anhelantes por Capurro, Malvín, Carrasco, que se acaban en el atardecer dramático y visionario de la Escollera 1 Oh Malyín en esas tardes de un sol rudo y dorado, cómo nos subía al corazón el amor de los árboles, de.las nubes blancas y el gran ojo azul y lleno de ternura del marl". 
Ahora el poeta está en su nuevo hogar, en el seno de su segunda patria, que lo acogen como a verdadero hijo, como a propio ciudadano, reconociéndole nacionalidad uruguara desde el principio, por derecho de americanidad y de poesía, títulos supremos en esa Atenas latina. Repuesto de su primera impresión de desencanto al venir de la magnificente Buenos Aires, pronto encuentra en Montevideo la ciudad a medida y tono con su alma y su temperamento, como lo dice en este fragmento de carta a su entrañable amigo el escritor Bernardo Canal Feijóo: " . . toda mi estadía en el Uruguay hasta ahora me ha sido sumamente grata. Montevideo es una ciudad que parece un nido. Toda se la podría pasear en dos horas; y luego, esa vista al mar por todo sitio . . . parece una obsesión de azul. Uno se siente más íntimo y mira con ojos de nevio a todas las cosas. Se gana en sensibilidad lo que se puede perder en fantasía".

Desde el primer instante entabla contacto fraternal con los poetas y escritores, que captan en los gestos, en las palabras, en las ideas del huésped la alia tensión eléctrica de su poesía inno. vadora y su espíritu de auténtico cantor latinoamericano. Carlos Sabat Ercasty, el épico cutor del gran canto sinfónico al Río de la Plata, con quien intima fervientemente; Julio Raúl Mendilaharsu, que antes de desaparecer prematuramente lega a su patria en $L a$ Cisterna una surgente de poesia Emilio Oribe, el insigne poetafilósolo-maestro, de portee aścéticon y lórazón/ tranciscano, humoristo y sabio; el gran luchador social de Rafael Barret; el alto genio lírico y novelístico de Jules Supervielle; la vasta y serena mentalidad y profunda cultura estética de Alberto Zum Felde; la bella y apasionada Safo meridional que es Juana de Ibarbourou; las figuras magistrales de Eduardo y Carlos Dieste, que en su revista Teseo fundan una cátedra libre de cultura; la mística doliente de Luisa Luisi, y tantos otros artistas le rodean y le envuelven con su sincero afecto $y$ con su aura espiritual.

No ya los intelectuales, escritores y periodistas, también los estadistas y políticos, enterados de lo que representan $y$ significan su persona y su obra para América Latina, lo protegen y prohijan, lo enrolan en la ciudadanía dírigente y lo alientan con su aplauso y su apoyo materíal: así el insigne repúblico Don José Battle Ordóñez, que con su imponente autoridad del tribuno del pueblo $y$ patriarca de su civilidad le abre en su Partido, en su periódico y en su casa un asiento de camarada y de hermano. 
Arraigado en su nueva tierra, embebido en su aguas y sus vic "tos, vibrando con los rayos de su cielo, absorbiendo las esencias físicas y culturales de su agro, plantado como vigoroso ombú en el reborde pampeano, que sacuden las ráfagas terrales, que estremecen los tremendos alisios, que inundan con sus largas marejadas el soberbio flumen argentor y el piélago de Atlas, trayéndole simultáneamente el mensaje americano y el verbo de Europa, yér. guese nuestro poeta y emite el cantar polirrítmico, en el cual la nueva generación liferaria de América reconoce su voz y su canción.

"Himnos del Cielo y de los Ferrocarriles", el libro primigenio y fundamental, es su evangelio, en el cual dice su buena nueva poética, en el cual vuelca un alma ofiebrada, encendida, cambiante, infinita, alacre, tenebrosa como el cielo, y trepidante, arrolladora, mayestática, vital, mortal y dinámica cual los ferrocarriles. Canta el dinamismo multiforme de la Vida y el Amor, simbolizando en la gran máquina celeste, en la portentosa maquinaria humana $y$ en su derivación y complemento, la maquinística industrial; $y$ en su juego coordinador celebra el triunto de la energía cósmica, que se ejerce con desinterés sublime, por el puro placer del ritmo múltiple, y que se expresa cabalmente en la exultante marcha herolca del maravilloso motor humano hacia el porvenir tlímite:

¡Motor de la explosión de toda la vida míal Hondo motor que haces mi cólera's 'mi llanto. mi callada pasión y mi fuerza y mi canto, tú, la máquina del único endero sin sendero; más ligero, más ligero, vo. to alado y scmgriento maquinista. con la carga de esperanza que es mi única conquista:

(Al Motor Maravilloso)

Canta a los héroes del nuevo tiempo, a los que traen renovada palaba de vida y de belleza: Walt Whitman, Miguel de'Unamuno, Woodrow Wilson; y al mismo tiempo alza sus loas férvidas al fútbol, máxima justa olímpica actual, que figura y representa en el estadio el advenimiento de la colectividad al gobierno político y la eficacia de su esfuerzo coordinado; a la mujer vegetal, que invita al amor de Naturaleza; a la motocicleta, loor de la libertad ilimitada, supremo afón de la especie: 


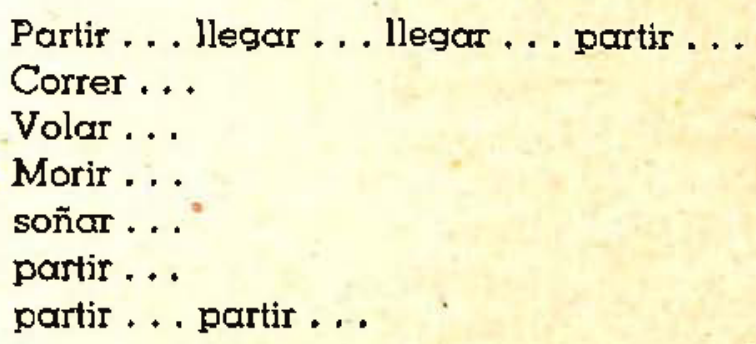

Y eleva su himno de homenaje a la Ciudad desposada con el Placer en la Fiesta de la Carne: su Canto al Carnaval, laureado por la Comuna montevideana.

Verano de 1925. Sábado de Carnaval. La Urbe, coronada de luceros y vestida con lentejuelas de electricidad, radiante de alegría y frenética de entusiasmo, impera deslumbradora en el cortejo rútilo de su Corso. Rúbricas $Y$ arabescos de fuegos multicolores prende la lluminación en plazas y avenidas; enciende miriadas de chispas en árboles y tablados; focos encandilantes en catés y bares y teatros, y enguirnalda con altas linternas las torres de los rascacielos. Inflama tambiên en los pechos una desaforada zed de goce y en las almas un quimérico anhelo de felicidad, $\alpha$ lentando una aimóstera mareante de júbilo. El Poeta es el Príncipe Bienvenido de la Fiesta; el Poeta ha triunfado sobre una legión de competidores en ePtorneo de la Poesiè y en la liza del Amor y va a poner su corona de laurel en la frente de su joven prometida. de simbólico nombre: Blanca Luz 1. . Su nombre está en todos los labios ... Y nos encontramos en el Café soberano de todas las "peñas" montevideanas, y nos estrechamos en abrazo interminable. Remembranzas de Lima, comentarios de Montevideo, frases trémulas de nostalgia y entusiasmo; y el poeta, no pudiendo contener la onda de su contento, desenvuelve ante su amigo de la adolescencia barranquina $y$ el pasmo de los parroquianos el pintoresco gobelíno de au Canto al Carnaval; con la rica orquestación de su voz, ejecuta el Poema Sinfónico del Festival montevideano:

Liberta maravillosa de la risa,

la ciudad corre en tus ruedas de colores, Carnava!l

... Otoño de 1925. El Poeta celebra sus desposorios con su prometida y como presente de boda le consagra su libro: "Blanca Luz". El romero ha encontrado su Madona, y le ofrece el ósculo de los peregrinos: 
Andarín de la luna

hoy me bajo por tí

$y$ en los ojos te beso

así...

Angeles finos

toquen tus párpados;

Días divinos

abran tus párpados.

(Serenata)

Pero ella, rayo de luz en su tarde, pcrecía apagársele y ruega:

Del sol es ella y es infinita como la tarde de luz y amor...

iDale Dios mío, salud bendita

bajo tu cálido resplandorl

$\infty$

(Serenata)

Con el presentimiento de la pronta separación, sueña en que habrán de encontrarse en el reino de los amantes de Peter Ybetson:

\author{
Más alláo del allá hos encentrábamos \\ solos y purps cinelli Converso" \\ como los ángeles que soñábamos. \\ Sangre hemos visto... \\ Sangre es el camino \\ donde se hizo blanco \\ nuestro solitario señor Jesucristo. \\ La muerte hemos visto: \\ sábanas pesadas de olvido $\mathrm{y}$ pavor ... \\ Relinchante nube negra nos seguía \\ tapándonos la estrella de puro temblor. \\ Penas hemos visto \\ que palidecian nuestro corazón; \\ -ella me decía ... \\ Pero allá, \\ - Y era azul su voz. \\ más allá nos encontrába̛mos \\ solos y puros \\ como los ángeles que soñábamos.
}



lume.

Es la voz celeste de Edgard Poe, cantando a Leonora y Ula-

... Invierno de 1925. Una tarde esplendente, uno de esos crepúsculos montevideanos, después que la lluvia ha llorrado todas sus lágrimas $\mathrm{y}$ el viento enjugado con sus gasas la faz del cielo; uno de esos ocasos en que el cielo de Montevideo con sus tapices de azul y gualda parece un pórtico del Paraíso, el Poeta ha volado a su paraíso. Por la ventana que franqueó su alma le llegaba el mensaje del cielo y de la tierra, tan amados. De los ángeles que soñaba y de los hombres que cantaba. Escribe su dulce hermana espiritual, Esther de Cáceres: "Ventana a una calle honda y viva y a unos crepúsculos encendidos y abjertos como el fuego ... Hasta aquella ventana, hasta aquella habitación llegaban en las tardes del domingo y como un clamor del mar las mil voces victoriosas del público del Estadio; y además la música fina de la noche; y la voz interrogante de los amigos".

Herido de muerte por sorda dolencia e impulsado por su fiebre andariega, había querido gastar sus últimas energías en auscultar el corazón campesino de la tierra que tonto quiso, que le acunó como a hijo y a la cual él, como hijo, dió su mejor tributo; y en el campo uruguayo cayó para morir besando su amado suelo.

El Poeta, hermano nuestro, se quedó a dormir su sueño sin ensueños, lejos de noșotros on el fardím matino del Cementerio del Buceo, bajo un palio de frondas que mecen con su hálito, como arrullándolo, las ventolinas del Río de la Plata y del Átlántico. El peregrino terminó su jornada; encendió el óleo de su vida a los pies de su Santa adorada y, por milagro del Arte, esa llama de Poesía arderá inextinguiblemente sobre su altar.

En el corazón del pueblo uruguayo escritores, estudiantes, obreros, empleados- vive el Poeta Iuan Parra del Riego con imperecedera vida; vive con vida perenne en los libros que editó el amor fraternal de sus compañeros, los artistas montevideanos; vive perdurablemente en la florida calle que sonríe allá en lo alto del Bulevar Artigas, ostentando el nombre de nuestro compatriota, y vivirá en la inmortalidad de la gloria del monumento que el afecto y la admiración de ese noble pueblo hermano va a erigirle.

"He caíds en mi ley", dijo el Poeta, al volver agonizante de la campiña uruguaya: y, en verdad, cayó en su ley: la ley de la fe en la vida, que es la Belleza; de la esperanza en la acción del hombre frente al misterio universal; del amor a la humonidad, fren- 
le al odio que pugna por destruírla; del heroísmo de la Alegría desnuda contra el Dolor rampante en las tinleblas; por eso cantó:

Yo soy el que puede, de repente, tírarlo todo atrás, libros, familia, amor, casa y amigos, solo por el placer viril de ensayar mi corazón en otros días solos y dramáticos.

Oh, querido Walt Whitmanl

IVoluntadl |Vigorl iAlegrial

¡Yo soy el que ha corrido por todas las ciudades gritándoles loco de esperanza a pobres poetos sin fuerza y sin luz la salud nueva de tus cantos purosl ¡Tus cantos donde han puesto la mano la tierra y el cielo!

\section{(Walt Whitman)}

Obediente a "su ley", pudo y supo escuchar sus "voces"; las voces de sú tiempo y de su era; las voces de sus maestros en Arte, que como al Florentino el Mantuano, le enseñaron el camino por donde el hombre se eterniza cantando la verdad de su mundo $y$ de su gente.

Obediente la lis tequ hube quedlejarse de su solar nativo en donde la ingomprensión y la malicia la envidia y el recelo, a. nublaban la estrella de su ruta; pero, a la distancia, por debajo de los Andes, sangraban de vez en cuando sus raíces, adheridas a la tierra natal; así, entre uno y otro de sus himnos, solloza nostálgicamenle su serenata:

A la mar me fuí con vela de colores...

de la tierra estaba sucio de luchar ...

Tercos sueños cazadores

dolorido de caminos y tambores,

yo la quería esperar.

Zuray Zurita, ¿no me oyes llorar?

Y le dije a la paloma y a la estrella:

mi corazón la quilere encontrar.

moribundo de canciones voy tras ella y es más muda que la muerte ty es tan bellal 
y es más fina que la mas.

Zuray Zurito

tno me oyes llorar?

(Serenata de Zuray Zurita)

$Y$ dice a su madre bienamada y lejana, besando con la añoranza, la luna de su cabeza cana, dormida en su corazón:

con tu remota ceniza dulce

quizá algún día me cure Dios.

(Lejos)

Pero, queridos amigos, ahora se opera el bello milagro. En este instante se realiza, por obra y gracia de la gracia y de la obra de la inteligencia y la cultura del Burgomaestre de Barranco, Doctor Estuardo Núñez y de sus dignos colegas consistoriales, el dulce prodigio, que sólo se efectúa en el orbe de la Religión y en el reino de la Puesía. El Poeta resucita, el poeta se alza de su lecho de reposo eterno del cementerio torestal y marino del Buceo uruguayo, $\mathrm{Y}$, en vuelo invisible, con sus alas de ángel del Arte, retorna de su exilio involuntario y vuelve, nuevo hijo pródigo, a su salar materno. Al llegar a las lindes de su amado Barranco salen a su encuentro, como hermomos y colegas, los poetas del Balneario, también en invisible vuelo, con sus plumas angélicas: Herrera, el melancólico, y Egaren elumiríticolix Fiansón, cel enamorado, y Bustamante, el exquisito, y Beingolea, el bueno, y el elegante Carrillo. $Y$, escoltado por la celeste pléyade, el Poeta ausente y olvidado se sienta de nuevo entre nosotros a comer el pan y beber el vino de nuestro ágape espiritual, para no alejarse más de su casa y su heredad, aquí, a la sombra del Puente del Amor, al amparo de los ficus paternales, en el corazón de la Bajada, creado por la cantinela de su mar, acariciado por la brisa pueblerina, besado por el cielo saludable, arrullado por las campanas lugareñas, bendecido por el Santo Párroco, y para siempre amado y recobrado por su querido pueblo barranquino. 